\title{
Accumulation of perfluoroalkyl compounds in Tibetan mountain snow: temporal patterns from 1980 to 2010
}

Xiaoping Wang ${ }^{1}$, Crispin Halsall ${ }^{2} * *$, Garry Codling ${ }^{2}$, Zhiyong Xie $^{3}$, Baiqing $X u^{1}$, Zhen Zhao ${ }^{3}$, Yonggang Xue ${ }^{1}$, Ralf Ebinghaus ${ }^{3}$, Kevin C. Jones $^{2}$

\footnotetext{
${ }^{1}$ Key Laboratory of Tibetan Environment Changes and Land Surface Processes, Institute of Tibetan Plateau Research, Chinese Academy of Sciences, Beijing 100101, China

${ }^{2}$ Lancaster Environment Centre, Lancaster University, Lancaster, LA1 4YQ, U.K.

${ }^{3}$ Helmholtz-Zentrum Geesthacht, Centre for Materials and Coastal Research GmbH, Institute of Coastal Research, Max-Planck Str. 1, D-21502 Geesthacht, Germany
}

* Address correspondence to: Tel: +86-10-84097072;

E-mail: wangxp@itpcas.ac.cn

** Address correspondence to: Tel: +44-0-1524594330;

E-mail: c.halsall@lancaster.ac.uk

Word account: text (5000) + 3Figures (900) + 1Tabel (300)=6200 

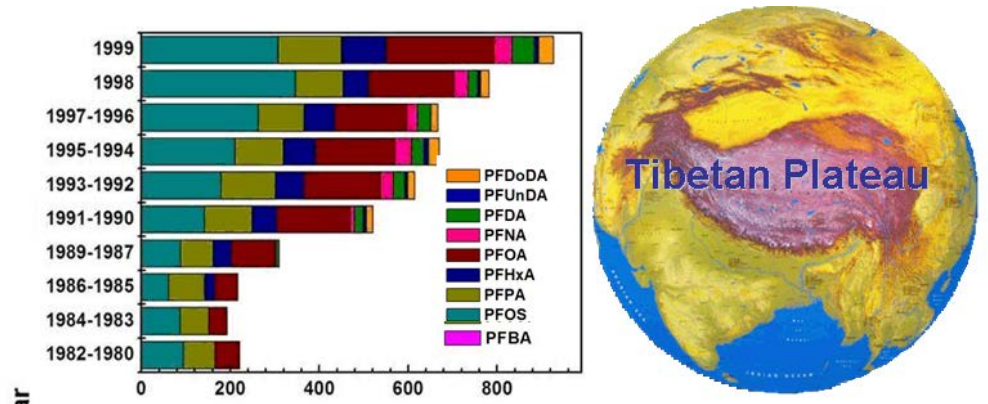

䒿

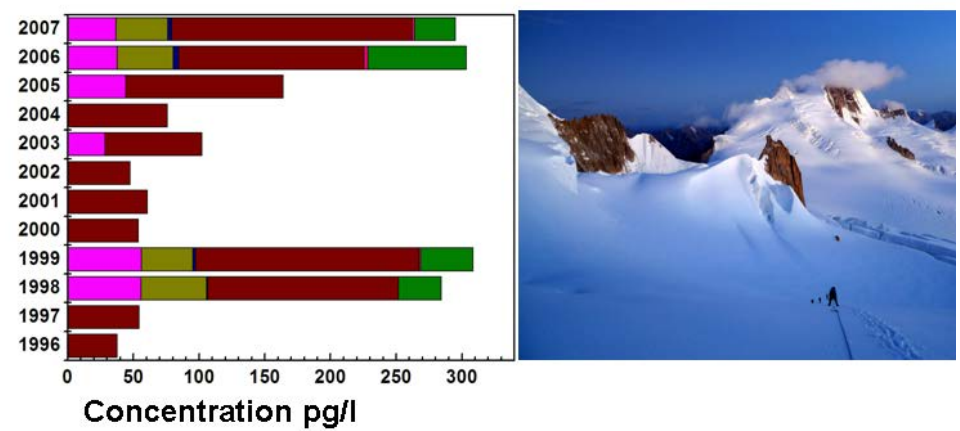

Table of Contents (TOC) Art 


\section{Abstract}

The use of snow and ice cores as recorders of environmental contamination is particularly relevant for per- and polyfluoroalky substances (PFASs) given their production history, differing source regions and varied mechanisms driving their global distribution. In a unique study perfluoroalkyl acids (PFAAs) were analysed in dated snow-cores obtained from high mountain glaciers on the Tibetan Plateau (TP). One snow core was obtained from the Mt Muztagata glacier (accumulation periods of 1980-1999), located in western Tibet and a second core from Mt. Zuoqiupo (accumulation periods of 1996-2007) located in south eastern Tibet, with fresh surface snow collected near Lake Namco in 2010 (southern Tibet). The higher concentrations of $\Sigma$ PFAAs were observed in the older Mt Muztagata core and dominated by perfluorooctane sulfonate (PFOS) (61.4-346 pg/L) and perflurooctanoic acid (PFOA) (40.8-243 pg/L), whereas in the Mt Zuoqiupu core the concentrations were lower (e.g. PFOA: 37.8-183 pg/L) with PFOS below detection limits. These differences in PFAA concentrations and composition profile likely reflect the downind-upwind sources affecting the respective sites (e.g. European/central Asian sources for Mt Muztagata and India sources for Mt Zuoqiupo). Perfluorobutanoic acid (PFBA) dominated the recent surface snowpack of Lake Namco which is mainly associated with India sources where the shorter chain volatile PFASs precursors predominate. The use of snow cores in different parts of Tibet provides useful recorders to examine the influence of different PFASs source regions and reflect changing PFAS production/use in the Northern Hemisphere. 


\section{Introduction}

Per- and polyfluoroalkyl substances (PFASs) are widely distributed in the global environment $^{1}$ and are present in both humans ${ }^{2}$ and a wide range of biota. ${ }^{3-5}$ Due to its persistence, its ability to undergo long-range transport (LRT) and its bioaccumulative behaviour, perfluorooctane sulfonate (PFOS) and perfluorooctane sulfonyl fluoride (POSF)-based chemicals which can degrade and form PFOS are now listed under Annex B of restricted substances of the UNEP Stockholm Convention on persistent organic pollutants (POPs). ${ }^{6}$ In remote environments like the Arctic, perfluoroalkyl acids (PFAAs) arise through a combination of LRT processes, including advection with surface ocean currents as well as transport in the atmosphere. ${ }^{7-10}$ In the atmosphere, PFAAs arise through the photochemical oxidation of volatile per- and polyfluoroalkyl precursors which are also subject to LRT. ${ }^{9,11-13}$ PFAAs may also be transported by the creation of marine aerosol derived from ocean surfaces, complicating the pathways by which these chemicals enter remote environments. ${ }^{14,15}$ However, for the continental interiors such as the Tibetan Plateau (TP) the influence of oceanic sources will be greatly diminished and PFAAs deposited to surfaces will have arrived through photochemical oxidation of volatile precursors and/or particle-mediated transport from source areas.

Given the lack of long-term systematic observations of PFAAs in air monitoring programmes then their depositional/accumulation history preserved in snow-ice presents a useful way to assess the hemispheric or global use history and to observe changing sources or use practices. Young et al. ${ }^{10}$ constructed an accumulation time series of $\mathrm{C}_{8}-\mathrm{C}_{12}$ PFAAs for perennial snow/firn on the Devon Island icecap in the Canadian Arctic. They observed a decrease in PFOS concentrations from 1998 to 2006, indicating a fast response in environmental concentrations following the phase out of POSF-chemicals in the late 1990s/early 2000s. ${ }^{10}$ The occurrence of perfluorodecanoic acid (PFDA) and perfluoroundecanoic acid (PFUnDA) in the Devon Island icecap indicate that atmospheric oxidation of volatile precursors is an important source of PFAAs to Arctic surfaces. ${ }^{10}$ More recently, Kirchgeorg et al. 16 measured PFAAs accumulation in snow collected from Colle Gnifetti glacier in the Swiss/Italian Alps. They observed a significant increase in the proportion of the shorter chain $\left(\mathrm{C}_{4}\right)$ perfluorobutanoic acid (PFBA) in the most recent years of the time-series and attributed this composition change to the increased release of PFBA (or precursors) by local sources. ${ }^{16}$ 
Snow and ice core records for chemical contaminants including POPs, have been obtained from temperate mountain environments. ${ }^{17-26}$ The TP has the largest aggregate of glaciers outside the Polar Regions with many of the mountain glaciers located at high altitudes where summertime temperatures do not routinely exceed $0^{\circ} \mathrm{C}$, thus reducing melt artefacts. TP is particularly interesting as this high altitude remote region allows an assessment of pollution impacts from Asia as well as the wider northern hemisphere and can make a useful comparison to deposition studies conducted in the European Alps ${ }^{16}$ and Arctic. ${ }^{10}$

Recently, organochlorine pesticides have been reported in ice-cores from the TP and their temporal patterns related to chemical use practices and abatement strategies. ${ }^{24}$ To date, the occurrence of the PFASs in lake fish of the Tibetan Plateau has been reported.$^{27}$ However, there is little or no information in the literature about levels of PFASs in mountain snow or ice of the Tibetan Plateau. In this study, snow cores and surface snow were sampled in the regions of Mt. Zuoqiupu (accumulation periods of 1996-2007), Muztagata glacier (accumulation periods of 1980-1999), and Namco (snow for 2010), respectively. The aim of this study was to determine the depositional history of PFASs over this time series and examine changes to chemical profiles given geographical differences among samples sites and the possible influence of difference PFAS-source regions.

\section{Methods}

Location of sampling sites. Three locations on the TP were chosen to investigate the temporal changes of PFASs (Figure 1). Snow cores were retrieved from the glaciers of Mt. Muztagata $\left(75.10^{\circ} \mathrm{E}, 38.28{ }^{\circ} \mathrm{N}, 6300 \mathrm{~m}\right.$, north-western $\left.\mathrm{TP}\right)$ and Mt. Zuoqiupu (96.92 ${ }^{\circ} \mathrm{E}$, $29.21^{\circ} \mathrm{N}, 5600 \mathrm{~m}$, south-eastern TP), while surface snow was collected near Lake Namco $\left(90.95^{\circ} \mathrm{E}, 30.73^{\circ} \mathrm{N}, 4800 \mathrm{~m}\right.$, southern TP). Details about the sampling locations are available as supporting information (SI, Figure SI-1). In general, snowfall on the northern and north-western parts of the Plateau is associated mainly with the westerly jet stream, which moves southward toward the Himalayas in winter (Figure 1). ${ }^{28}$ Thus, glaciers on the southern plateau can receive precipitation through air masses from the south via the Indian monsoon during summer and from the west during winter (Figure 1). ${ }^{28}$ As a result, due to the different upwind airsheds, these three snow sampling sites may differ with regards to their contaminant loading and profile due to the influence of different source regions.

Sampling methodology. In September 1999, a $22.4 \mathrm{~m}$ snow core was retrieved at Mt. 
Muztagata and a snow core of $30 \mathrm{~m}$ was collected in May of 2007 at Mt. Zuoqiupu. These scientific expeditions were organized by the Chinese Academy of Sciences (CAS). After the drilling, pre-combusted Al foil envelopes were employed for core handling in the field to minimize contamination. Snow core samples were packed in double-sealed polyethylene bags and transported frozen to the laboratory by refrigerated trucks. Preparation of snow core samples was carried out in a cold room $\left(-20^{\circ} \mathrm{C}\right)$. Snow cores $(\mathrm{ID}=9 \mathrm{~cm})$ were mechanically peeled into three parts (the outer, middle materials and the inner core). The inner core was kept frozen in the dark in pre-cleaned glass jars until analysis. The outer and the middle parts of the snow core were cut into sections at $5 \mathrm{~cm}$ intervals for the measurements of $\delta{ }^{18} \mathrm{O}$ for core-section dating. Based on the dating results (see below), the inner core was melted and extracted for PFASs. Details about the snow core is given in Table SI-1.

Snow samples were collected in December 2010. During November-December 2010, snow samples were collected during 3 snow events. Heavy snowfalls resulting in snow depth accumulations of $\sim 31 \mathrm{~cm}$ and $40 \mathrm{~cm}$ occurred on 24 November and 10 December, respectively. Snow samples were collected vertically and obtained by excavating a snowpit down to the ground. The snowpit was dug to a depth of $86 \mathrm{~cm}$. The pit wall was sub-sampled with a stainless-steel cube (volume: $1 \mathrm{~L}$ ) at $10 \mathrm{~cm}$ intervals over the entire vertical profile. Approximately $4 \mathrm{~L}$ of snow were collected for each sample. The snow samples were transported to the laboratory in pre-rinsed stainless-steel containers and left to melt at room temperature. Snow depth (in water equivalents) and snow density were determined for each sample as described in Table SI-2. To avoid contamination, materials with fluoropolymer coatings and fluoropolymer products were strictly avoided at Namco.

Snow Core Dating. Snow core dating was achieved via the annual layer counting that is made from the continuous concentration profiles of seasonally varying $\delta{ }^{18} \mathrm{O}$. A preliminary time-depth profile of the ice core was achieved by assigning to the surface of the core a time point of 1999 and 2007 (the time of drilling) for the Mt. Muztagata glacier and Mt. Zuoqiupu glacier, respectively. The $\delta^{18} \mathrm{O}$-depth profiles are shown in Figure SI-2. For the Mt. Muztagata glacier, the ${ }^{18} \mathrm{O}$ isotopic ratio displayed a seasonal trend, marked by higher values in summer precipitation and lower values in winter (Figure SI-2) ${ }^{29}$ However in the Mt. Zuoqiupu core a more depleted $\delta{ }^{18} \mathrm{O}$ isotopic ratio occurs during the summer periods with higher values during the winter, reflecting the influence of the summertime monsoon season, 
${ }^{30}$ (for further details see Figure SI-2). The seasonality of $\delta{ }^{18} \mathrm{O}$ details the approximate annual layers and provides a basis for dating. Using the seasonal fluctuations of $\delta{ }^{18} \mathrm{O}$ along the profile, the 30-m snow core of Mt. Zuoqiupu was dated to 12 years (from 1996 to 2007, Figure SI-2) and the 22.4-m snow core of Mt. Muztagata was dated to 20 years (from 1980 to 1999, Figure SI-2). The processes that may lead to dating uncertainties are provided in Text SI-1.

According to the dating results, the annual accumulation for these two snow cores differed from each other. Mt. Zuoqiupu snow core had the highest accumulation, with the highest SWE of $11.9 \mathrm{~kg} \mathrm{~m}^{-2} \mathrm{yr}^{-1}$ in 2004 (Table SI-1). However, the Mt. Muztagata snow core had a water equivalent accumulation of 2.6-6.3 $\mathrm{kg} \mathrm{m}^{-2} \mathrm{yr}^{-1}$, approximately a third to a half of that accumulated for Mt. Zuoqiupu (Table SI-1). Therefore, in order to achieve sufficient melt water ( $>2 \mathrm{~L}$ ) for PFC analysis, the Mt. Muztagata snow core sections representing 2 to 3-years of accumulation were combined and melted (see Table SI-1 and Figure SI-2). Immediately after melting, the water sample was filtered through a quartz fibre filter (QFF) (previously baked at $450^{\circ} \mathrm{C}$ ). Filter samples were also extracted for PFASs and the amount of particulate matter for each sample was also measured and provided in Table SI-1.

Three kinds of blanks were prepared in this study, namely deep snow/ice meltwater blank, ground-water blank and laboratory blanks. Deep snow/ice was taken from $~ 100 \mathrm{~m}$ depth and represented snow that was $>100$ and $\sim 60$ years old for Mts. Muztagata and Zuoqiupu glaciers, respectively. The ground water ( $\sim 60 \mathrm{~m}$ depth) was collected from the Lake Namco region, close to the surface snow sampling site of this study (Figure SI-1). In each case 2L of melted deep-snow water and ground water were used as blanks. Laboratory blanks were generated by spiking the PFASs recovery standard directly into SPE cartridges and following an extraction process identical to the real samples. In total, 6 melted deep snow water blanks, 3 ground water blanks and 6 laboratory blanks were prepared to test for contamination artefacts and to generate limits of the detection (LOD).

Sample Extraction. Filtered metwater samples were subject to solid phase extraction (SPE) using Waters Oasis WAX cartridges ( $150 \mathrm{mg}, 6 \mathrm{~cm}^{3}, 30 \mathrm{~mm}$ ), akin to methods described elsewhere. ${ }^{31}$ Prior to extraction, the samples were spiked with $400 \mathrm{pg}$ absolute of a recovery standard (RS) mix (Table SI-3). After preconditioning with $5 \mathrm{~mL} \mathrm{MeOH}$ and $5 \mathrm{~mL}$ distilled Millipore water, the SPE cartridge was loaded with the water sample (2-Llitters) and eluted at 1-2 drops per second, after which each cartridge was washed with $0.1 \%$ acetic acid and 
dried for 20 minutes under vacuum. The cartridges and filters were then wrapped in Al-foil and sealed into air-tight containers with dry ice and transported to the Helmholtz-Zentrum Geesthacht, Germany. The cartridges and filters were stored at $-20^{\circ} \mathrm{C}$ until extraction. Each cartridge was then air dried for 30 min under vacuum. For this operation an additional WAX cartridge was connected to the top of the sample cartridge to ensure that the air stream was free of PFASs. ${ }^{32}$ Analytes were eluted from the WAX cartridges using $10 \mathrm{~mL} \mathrm{MeOH}$ with $0.1 \%$ ammonium hydroxide. The extracts were concentrated to $200 \mu \mathrm{L}$ by nitrogen and spiked with $20 \mathrm{ng}$ absolute of the injection standard ${ }^{2} \mathrm{H}$-perfluoro-[1,2- $\left.{ }^{13} \mathrm{C}_{2}\right]$-2-decenoic acid (8:2FTUCA) (50 $\mu \mathrm{L}$ of a $0.4 \mu \mathrm{g} / \mathrm{mL}$ solution, Table SI-3). The QFF were spiked with the same RS mix and sonicated with $20 \mathrm{~mL}$ of $\mathrm{MeOH}$ for $30 \mathrm{~min}$. This extraction was performed three times and these 3 fractions were combined and reduced by rotary evaporation. Finally, the extract was reduced to $200 \mu \mathrm{L}$ under a gentle stream of nitrogen and spiked with the injection standard mentioned above.

Instrument analysis. Detials of the instrumental analytical method has been described in elsewhere. $^{33}$ Briefly, an HP 1100 HPLC-system (Agilent Technologies) was used with a Synergi Hydro RP C1 8 80A column $(150 \times 2 \mathrm{~mm}, 4 \mu \mathrm{m}$, by Phenomenex), combined with a suitable guard column (Synergi $2 \mu$ Hydro RP Mercury, $20 \times 2 \mathrm{~mm}, 2 \mu \mathrm{m}$ ). Modifications of the HPLC system were made by removing Teflon parts to eliminate instrumental blank contamination. The triple-quadrupole mass spectrometer [Applied Biosystems/MDS SCIEX (API 3000)] was operated in electrospray ionisation (ESI) in negative ionisation mode. Quantification was performed using response factors calculated and applied to an 8-point calibration curve ranging from 0 to $15 \mathrm{pg}^{-1}$ for individual analytes. Target analytes included the $\mathrm{C}_{4}-\mathrm{C}_{14}$ perfluorocarboxylic acids (PFCAs) and $\mathrm{C}_{4}-\mathrm{C}_{10}$ perfluorosulfonic acids (PFSAs). A full list of analytes is provided in Table SI-4.

Quality controls and assurance. Recovery of each spiked sample was provided in Table SI-5 and blank values are provided in Table SI-6. Compounds were classified as not detected (ND) when a signal to noise ratio $(\mathrm{S} / \mathrm{N})$ was $<3$. Only PFOA was detected in the laboratory blanks, while PFOS, PFBA, perfluoropentanoic acid (PFPA) and PFOA were detected in melted deep snow water (DSW) blanks. The limit of detection (LOD) was then quantified as the standard deviation of the average DSW blank. If chemicals were not detected in the DSW blanks, the LOD was calculated as a S/N ratio of 10 . The LODs based on a $2 \mathrm{~L}$ water sample 
were $25 \mathrm{pg} / \mathrm{L}$ for PFOS and PFPA, 15pg/L for PFBA, 5pg/l for PFUnDA, $10 \mathrm{pg} / \mathrm{L}$ for PFOA, PFNA and PFDoDA, and $20 \mathrm{pg} / \mathrm{L}$ for the other PFAAs. Table SI-7 provides the average blank concentrations and the corresponding LODs expressed as $\mathrm{pg}-/ \mathrm{L}$. The LOD values reported here are similar to those reported by previous studies and the overall analytical quality has been assured through participation in inter-laboratory studies. ${ }^{10,33-35}$ The blank test indicated that field sampling did not result in contamination of the samples. No background contamination was detected in the filter blanks for the particulate phase. In the present study, a total of 6, 8 and 11 PFAAs of the 16 PFAAs in the standard were quantified in the Zuoqiupu glacier snow core, Muztagata snow core and fresh snow samples, respectively (all samples were blank corrected with, for-further details presented insee SI Tables SI 8-10). Recoveries ranged between $29-155 \%$ for recovery mix (see SI Table SI-5). All results were recovery corrected. Duplicate measurements were conducted on 15 paired samples (see Tables S-11 and S-12). The relative standard deviation between the duplicates was $5-40 \%$, 4-48\% for the Mt. Zuoqiupu andsnow core,-Mt. Muztagata snow core samples (Tables SI-13, SI-14), respectively, and 6-47\% for triplicate fresh snow samples from Namco (see Table SI-10).

\section{Results \& Discussion}

Overview to the Tibetan Plateau and pollution sources. Interpretation of the temporal changes of pollutants in a snow core depends on knowledge of the meteorology and major emission sources. The highest snowfall/precipitation on the Plateau coincides with the Indian monsoon, which reaches about $32{ }^{\circ} \mathrm{N}$ during summer (Figure 1). ${ }^{36}$ However, snowfall on the northern and north-western parts of the plateau is associated mainly with the westerly air masses (Figure 1). Thus, wet deposition of airborne contaminants to Tibetan glaciers derives primarily from two directions: west and south. For example, Xu et al. ${ }^{30}$ attributed decreased carbonaceous particle concentrations on the Muztagata glacier in the 1970s-1980s to diminished European sources following the rise in European environmental regulations ${ }^{30}$. In addition, $\mathrm{Pb}$ has been detected in an ice core from Mt. Muztagata. The temporal trends showed increasing $\mathrm{Pb}$ concentrations from 1955 to 1993, with a decrease after $1993 .{ }^{37}$ This variation was closely associated with the anthropogenic emissions from countries in Central Asia. ${ }^{37}$ On the other hand, pollutant source regions affecting the south-eastern Plateau have been largely assigned to south Asia. ${ }^{38}$ For the Zuoqiupu glacier, the southern branch of the westerlies that sweep over the south side of the Himalaya-Hindu Kush range (Figure 1) 
combined with the Indian monsoon make the Zuoqiupu site a receptor of south Asian sources. ${ }^{30}$ This raises important questions with regards to PFAA contaminants. For example, can PFA profiles obtained from different snow cores across the TP reflect the influence of their corresponding source regions (Asian or European)? Recently, there is evidence that manufacturing of PFAAs has shifted from longer chain chemicals ( $\mathrm{C}_{8}$ and above) to shorter chain ones $\left(\mathrm{C}_{4}\right)^{39,40}$ and manufacturing output has increasingly centred on Asian countries. ${ }^{39}$, 41-43 Similarly, can the Tibetan snow record these shifts? Comparison of the PFAA concentrations, deposition fluxes and congener profiles of this study with other remote regions, such as the Arctic and European Alps, should provide a better understanding of the influence of different or changing sources across the Northern Hemisphere.

PFA concentrations in snow. The full dataset of the measured PFA concentrations in the Tibetan snow are available as Tables SI 8-10 (Supporting Information). Concentrations of the $\Sigma$ PFAAs in the Mt. Muztagata (western Tibet, accumulation periods of 1980-1999) snow ranged from 193 to $927 \mathrm{pg} / \mathrm{L}$, while those in the Mt. Zuoqiupu glacier (south eastern Tibet, accumulation periods of 1996-2007) were markedly lower ranging from 37.8 to $370 \mathrm{pg} / \mathrm{L}$. Relatively higher PFAA concentrations in the snow core of Mt. Muztagata may be due to the influence of the prevailing westerlies and the influence of upwind European sources during the earlier snow accumulation period. ${ }^{30}$ The concentrations of PFAAs in the present study were compared with those observed in Polar and remote regions and provided in Table 1. The PFAA concentrations in the Mt. Zuoqiupu glacier are similar to the concentrations reported for the Devon Island icecap (Canadian Arctic, accumulation period of 1996-2006). ${ }^{10}$ However, concentrations of $\Sigma$ PFAAs in the Mt. Muztagata glacier are higher than those of the Devon Island study ${ }^{10}$ but lower than those observed in a recent snow core from the Colle Gnifetti located in the Swiss/Italian Alps (accumulation range: 1996-2008). ${ }^{16}$ PFAA emissions from European countries are likely to account for the higher levels of PFAAs observed in the Colle Gnifetti snow core ${ }^{16}$ and support the assumption that higher levels observed in the older Mt Muztagata core are due to the influence of a European signal. Snow and rainfall are important wet depositional sources of PFAAs ${ }^{44}$ and have been measured at several locations across the Northern Hemisphere. ${ }^{42}$ Generally, high concentrations of PFAAs were found in urban areas with much lower concentrations reported for precipitation analysed from remote regions. The concentrations of $\Sigma$ PFAAs measured in both Mt. Muztagata and Mt. Zuoqiupu glacier snow were lower than those observed in precipitation 
(collected in 2002) from remote parts of Canada ${ }^{42}$ as well as the lake water from a glacier-fed lake in the North American Rockies. ${ }^{45}$ In this study, the surface fresh snow samples collected at Namco contained $\Sigma$ PFAAs concentrations up to $4236 \mathrm{pg} / \mathrm{L}$, which is similar to concentrations observed in surface snow from the Arctic- ${ }^{46}$ and Antarctic. ${ }^{47}$ These comparisons indicate that concentrations of PFAAs in contemporary snow in the south eastern part of the TP are akin to those observed in the Polar Regions indicating the remoteness of this region.

Time-series and PFC depositional fluxes. Depth concentrations of PFAAs measured on the Tibetan glaciers are shown in Figure 2 with data provided in Tables SI 8 and 9. For the Mt. Muztagata snow core, concentrations of $\Sigma$ PFAAs increased continuously over the time period studied (see Figure 2a). Similar results were observed for individual PFAAs, such as PFOA and PFOS (Figure SI-3) and in broad agreement with the time series of global emissions for PFOA and PFOSF-based substances. ${ }^{48}$ This finding generally supports the time-series of PFOS concentrations observed in selected Arctic biota, whereby PFOS levels have been observed to increase in Arctic ringed seals (Phoca hispida) up to the year 2000 before levelling off or declining. ${ }^{49}$ It must be noted however, that there are geographic disparities across the Arctic with regards to temporal trends of PFAAs in biota. ${ }^{49}$ For Mt. Zuoqiupu, the time-series of $\Sigma$ PFAAs concentrations in the snow core can be broadly broken down into three periods (Figure 2b). An increase was observed from 1996 to 1999, followed by a sharp decrease from 2000 to 2004 and then a marked increase from 2005 onwards. The snow core of Mt. Zuoqiupu, (located in south-eastern TP) showed evidence of melting, with layers of ice marking freeze-thaw events in sections of the core (see description of the snow core, Table SI-1). Air temperatures during the summer regularly exceed $0^{\circ} \mathrm{C}$ resulting in seasonal snow melt. It is therefore plausible that some PFAAs may have migrated down the snow core thereby altering their vertical and hence temporal distribution. From Table SI-1, melting was clearly apparent within sections of the core dated as 1998 and 1999, i.e. ice layers of 87 and $80 \mathrm{~cm}$ thick respectively were present in each of the core sections. The presence of ice layers will impede the percolation of meltwater from above, preventing further movement of soluble contaminants down the snow core and resulting in accumulation of PFAAs at these key layers. ${ }^{50}$ This process may account for the elevated concentrations observed for the 1998/1999 layers and is supported to some extent by the PFAA profile in these layers which contain the more soluble, shorter chain compounds of PFBA $\left(\mathrm{C}_{4}\right)$ and 
PFPA $\left(C_{5}\right)$. These compounds are absent from the adjacent snow layers above (e.g. 2000 to 2004). Nonetheless, higher concentrations of $\Sigma$ PFAAs occur in the uppermost snow layers (e.g. 2005-2007), which are 5-fold higher than concentrations in the middle layers (2000-2004), with PFOA concentrations increasing markedly from 2005 to 2007 (Figure 2b). This later increase in the uppermost snow layers may be due to the growing influence of atmospheric perfluoro-precursor sources in Asia, ${ }^{51}$ which will particularly affect PFAA levels in the Mt Zuoqiupu area given its location in south-eastern Tibet.

Annual deposition fluxes, calculated on the basis of measured concentrations of individual PFAAs and the annual water equivalent accumulation are shown in Table SI-15. The Mt. Muztagata snow core showed higher $\Sigma$ PFAA deposition fluxes, with the maximum of 58755 $\mathrm{fg} \mathrm{cm}^{-2} \mathrm{yr}^{-1}$ (Table SI-15) whereas deposition fluxes of $\Sigma$ PFAAs for the Mt. Zuoqiupu snow core ranged from 13575 to $41982 \mathrm{fg} \mathrm{cm}^{-2} \mathrm{yr}^{-1}$ (Table SI-15). The annual water equivalent accumulation for the Mt. Zuoqiupu snow core was 2 3 times higher than that of Mt. Muztagata (Table SI-1). However, due to the markedly lower PFAA concentrations in Mt. Zuoqiupu snow (Table SI-8 and 9) then the deposition fluxes were therefore lower and support the argument that different source regions influence the PFAA concentrations rather than simple differences in snow accumulation rates. The deposition fluxes of $\Sigma$ PFAAs in these Tibetan glacier snow cores are similar to those reported for the Devon Island icecap, ${ }^{10}$ but lower than Colle Gnifetti in the Italian Alps ${ }^{16}$ and other depositional fluxes observed in temperate areas (Table SI-15).$^{42,44}$

PFAA composition in snow. The dominant PFAAs in the Mt. Muztagata glacier snow core were PFOS followed by PFOA and PFPA, (Figure 2a), contributing 34\% (27-45\%), 26\% (21-32\%) and 22\% (13-37\%) to the $\Sigma$ PFAAs, respectively. Short chain-PFAAs, such PFBA and PFBS were not detected in the Muztagata snow core, while the longer chain PFAAs ( $\Sigma\left(\mathrm{C}_{10}\right.$-PFDA, $\mathrm{C}_{11}$-PFUnDA and $\mathrm{C}_{12}$ PFDoDA), comprised $<8 \%$ of the total PFAAs. In the Mt. Zuoqiupu glacier snow core, PFOA was the dominant species (Figure 2b), comprising 77\% (38-100\%) of the $\Sigma$ PFAAs, followed by PFBA (average: 18\%, range: $0-27 \%$ ) and PFPA (average: 5\%, range:0-16\%). Interestingly PFOS was found at significant concentrations in the entire snow core for Mt Muztagata (61.4-347 pg/L) but was below detection limits for Mt Zuoqiupu. This reflects the older time-series at Muztagata (1980-1999 snow accumulation period) and the influence of upwind Eurasian source regions prior to the significant reduction 
in POSF-based chemicals production in the early 2000s. ${ }^{52}$ Low levels of PFOS (25-64 pg/L) were detected in the surface/fresh snow sampled at Lake Namco, located in the central region of the TP, and are broadly comparable to concentrations recently measured in Arctic snow (see Table 1). The PFAA profile in the surface snow of Lake Namco was dominated by the $\mathrm{C}_{4}-\mathrm{C}_{7}$ PFCAs, particularly PFBA which displays the highest concentrations (913-2569 pg/L) for all the PFCs reported in this study (see Figure 3). The average proportion of PFA species in Namco surface snow was as follows: PFBA (61\%), PFHpA (17\%), PFPA (7\%), PFHxA (4\%), PFOA (5\%), and PFNA (2\%). Given snow samples were collected relatively recently (December 2010), then the dominance of the shorter chain compounds (e.g. PFBA) may be attributed to the shift in manufacturing towards shorter chain products such as the volatile fluorotelomer alcohol, 4:2FTOH, recently measured in ambient air in India. ${ }^{51,53}$

Sources of PFAAs to the TP. Unlike the marine environment of the Arctic where surface ocean currents play an important role in providing PFAAs to the Polar environment, the Tibetan Mountain glaciers will receive PFAA contaminants solely from the atmosphere. The Tibetan PFAAs could therefore arise from: i) the atmospheric oxidation of gas-phase volatile precursors,${ }^{54}$ followed by dry and wet deposition; the latter driven largely by snowfall; 2) the direct transport of gas-phase and/or aerosol-associated PFAAs. ${ }^{55}$ In this study, particulate matter in the snow was subject to PFAA analysis. Particle concentrations in the Namco snow samples were relatively high with concentrations of $\sim 100 \mathrm{mg} / \mathrm{L}$ (see Table SI-2) while concentrations in the Mt. Zuoqiupu snow core $(<10 \mathrm{mg} / \mathrm{L})$ were lower than those of Mt. Muztagata $(<50 \mathrm{mg} / \mathrm{L})$. However, in all cases, PFAAs were not detectable in the filtered particles. This is akin to other studies that have reported negligible PFAA concentrations associated with atmospheric particulate matter collected in the remote ocean atmosphere. ${ }^{33,56}$ However, the low particle mass collected from the low-volume samples (2L) in this study could be responsible for the non-detects reported here. Nonetheless, the non-detects for particle-bound PFAAs indicate that the majority of PFAAs in the snow are present largely as a result of direct atmospheric transport in the gas-phase and/or atmospheric photooxidation of volatile precursors (i.e. FTOHs, fluorotelomer arcylates, olefins and iodides in the case of perfluorocarboxylic acids). As measurements of gas-phase PFAAs in remote air are rarely reported or are below the detection limit ${ }^{57,58}$, then the atmospheric photooxidation pathway of neutral precursors probably accounts for the majority of PFAAs measured in contemporary Tibetan snow. At present it is not clear whether this process occurs in the gas phase with 
subsequent scavenging of the PFAAs by snowfall, or a heterogeneous reaction occurring on ice-crystal surfaces, or some combination of the two. Air masses over the TP are mainly dominated by continental air from central Asia/Europe (western Tibet) and maritime air from the Indian Ocean (southern Tibet). ${ }^{59}$ The Mt. Muztagata snow core represents the earlier accumulation period from_1980 to 1999 and given its location in the western side of the TP this would account for the dominance of PFOS and PFOA - present in the environment through a wide variety of products and applications across Europe over this time period. ${ }^{52,60}$ However, the Mt. Zuoqiupu snow core (1996 to 2007) is dominated by PFOA, with marked contributions of PFBA and PFPA in the 2005-07 layers. The lack of PFOS in this core likely indicates the decline in the presence of PFOS (or its precursors) in the atmosphere of the Northern Hemisphere in recent years, as well as the influence of different source regions affecting this part of the TP, e.g. sources in south Asia and India. Although PFOS was detected in snow core samples from Zuoqiupu the relatively high LOD for PFOS prevented its quantification and reporting._While the phase out of longer chain $\mathrm{C}_{8}$-based fluoro chemicals maybe gaining momentum globally, both 8:2 FTOH and 10:2 FTOH were still the dominant compounds in ambient air across Japan, China and India in 2009, ${ }^{51}$ although, interestingly, 4:2 FTOH was the most abundant fluorotelomer alcohol measured at sites in India. ${ }^{51}$ The dominance of PFBA in the fresh snow at Namco is likely to be attributed to the photooxidation of 4:2 FTOH with the incursion of air masses from the Indian sub-continent. This is most relevant during the Indian Monsoon period ${ }^{61}$ which is a driving force for the atmospheric transport of pollutants from south Asia to the TP. ${ }^{38}$ The lack of PFOS as well as the shorter chain PFSAs in the Mt Zuoqiupu core, and the coincidently low levels of PFOS observed in the surface snow of Namco, may be due to the relatively lower amounts of fluorooctane sulfonamide (FOSA/E) and fluorobutane sulfonamide (FBSA/E) precursors in contemporary Indian air. ${ }^{51}$ From the study of $\mathrm{Li}$ et $\mathrm{al}^{51}$, the air concentrations of these chemicals across India were low (aside from several point sources) and fall within the same ranges observed in contemporary European/North American studies, ${ }^{51}$ which may account for the low levels of PFOS observed at Namco and Zuoqiupu.

As an indicator of related sources, a correlation matrix was undertaken for the PFAA data from the Mt Muztagata and Mt Zuoqiupu snow cores respectively (Table SI-16 and 17). Specifically, correlations were high $(r>0.80, p<0.01)$ between PFOS and PFOA for Mt. Muztagata, moreover, PFBA showed higher correlations $(r>0.80, p<0.01)$ with PFOA and PFHxA for Mt. Zuoqiupu. This implies that these chemicals arise from similar sources and/or 
have experienced similar precursor oxidation and deposition processes.

PFAAs are present and have accumulated in mountain snow across Tibet over the last 30 years, although there are clear regional differences across the Plateau in terms of the quantity of PFAAs deposited and their composition, and this is not solely due to differences in snow accumulation rates between the two study sites. The evidence here would suggest that different source regions affect different parts of the TP, with an earlier European signal in the west and an Indian/south Asian signal in the south and east. PFAA concentrations and accumulation fluxes have increased over the respective snowcore time series, with the highest IPFAA concentrations in the surface snow (2010) from Namco. The PFA composition at this site, however, is dominated by the shorter chain PFBA, in marked contrast to the older accumulated snow at Mts. Muztagata and Zuoqiupu. This reflects the abundance of 4;2 FTOH in air across India and a shift to shorter chain-length chemicals. The presence of PFBA in snow is in agreement with findings from a snow core study conducted recently in the European Alps. ${ }^{16}$ Further monitoring at the Mt. Muztagata site would be useful in order to determine the contemporary European signal on western Tibet and to assess whether PFAAs in the snowpack show a shift towards the shorter chain length chemicals. PFASs accumulation in snow will provide a source of these chemicals to mountain lakes and catchment headwaters, and studies aimed at quantifying this transfer to freshwater habitats are now recommended.

\section{Acknowledgement}

This study was supported by the National Natural Science Foundation of China (41222010 \& 41071321) and the UK Natural Environment Research Council grant 'ArcPOP' NE/E00511X/1. GC was supported by the NERC Doctoral Training Grant: NE/H526127/1.

Supporting Information. The details about the sampling sites, snow cores and tables containing the chemical concentrations in blanks and snow cores, and the comparison of deposition fluxes are presented. This information is available free of charge via the Internet at http://pubs.acs.org/.

\section{References}


(1) Ahrens, L., Polyfluoroalkyl compounds in the aquatic environment: a review of their occurrence and fate. J. Environ. Monitor. 2011, 13, (1), 20-31.

(2) Olsen, G. W.; Lange, C. C.; Ellefson, M. E.; Mair, D. C.; Church, T. R.; Goldberg, C. L.; Herron, R. M.; Medhdizadehkashi, Z.; Nobiletti, J. B.; Rios, J. A.; Reagen, W. K.; Zobel, L. R., Temporal trends of perfluoroalkyl concentrations in American red cross adult blood donors, 2000-2010. Environ. Sci. Technol. 2012, 46, (11), 6330-6338.

(3) Hart, K.; Kannan, K.; Tao, L.; Takahashi, S.; Tanabe, S., Skipjack tuna as a bioindicator of contamination by perfluorinated compounds in the oceans. Sci. Total Environ. 2008, 403, (1-3), 215-221.

(4) Kannan, K.; Perrotta, E.; Thomas, N. J., Association between perfluorinated compounds and pathological conditions in Southern Sea otters. Environ. Sci. Technol. 2006, 40, (16), 4943-4948.

(5) Müller, C. E.; De Silva, A. O.; Small, J.; Williamson, M.; Wang, X.; Morris, A.; Katz, S.; Gamberg, M.; Muir, D. C. G., Biomagnification of perfluorinated compounds in a remote terrestrial food chain: Lichen-caribou-wolf. Environ. Sci. Technol. 2011, 45, (20), 8665-8673.

(6) Zushi, Y.; Hogarh, J. N.; Masunaga, S., Progress and perspective of perfluorinated compound risk assessment and management in various countries and institutes. Clean Technol. Environ. Policy 2012, 14, (1), 9-20.

(7) Benskin, J. P.; Muir, D. C. G.; Scott, B. F.; Spencer, C.; De Silva, A. O.; Kylin, H.; Martin, J. W.; Morris, A.; Lohmann, R.; Tomy, G.; Rosenberg, B.; Taniyasu, S.; Yamashita, N., Perfluoroalkyl acids in the Atlantic and Canadian Arctic oceans. Environ. Sci. Technol. 2012, 46, (11), 5815-5823.

(8) Prevedouros, K.; Cousins, I. T.; Buck, R. C.; Korzeniowski, S. H., Sources, fate and transport of perfluorocarboxylates. Environ. Sci. Technol. 2006, 40, 32-44.

(9) Wania, F., A global mass balance analysis of the source of perfluorocarboxylic acids in the Arctic ocean. Environ. Sci.Technol. 2007, 41, (13), 4529-4535.

(10) Young, C. J.; Furdui, V. I.; Franklin, J.; Koerner, R. M.; Muir, D. C. G.; Mabury, S. A., Perfluorinated acids in Arctic Snow: new evidence for atmospheric formation. Environ. Sci. Technol. 2007, 41, (10), 3455-3461.

(11) Ellis, D. A.; Martin, J. W.; De Silva, A. O.; Mabury, S. A.; Hurley, M. D.; Sulbaek Andersen, M. P.; Wallington, T. J., Degradation of Fluorotelomer Alcohols: A likely atmospheric source of perfluorinated carboxylic acids. Environ. Sci. Technol. 2004, 38, (12), 3316-3321.

(12) Wallington, T. J.; Hurley, M. D.; Xia, J.; Wuebbles, D. J.; Sillman, S.; Ito, A.; Penner, J. E.; Ellis, D. A.; Martin, J.; Mabury, S. A.; Nielsen, O. J.; Andersen, M. P. S., Formation 
of $\mathrm{C7F} 15 \mathrm{COOH}$ (PFOA) and other perfluorocarboxylic acids during the atmospheric oxidation of 8 : 2 fluorotelomer alcohol. Environ. Sci. Technol. 2006, 40, (3), 924-930.

(13) Del Vento, S.; Halsall, C.; Gioia, R.; Jones, K.; Dachs, J., Volatile per- and polyfluoroalkyl compounds in the remote atmosphere of the western Antarctic Peninsula: an indirect source of perfluoroalkyl acids to Antarctic waters. Atmos. Pollut. Res. 2012, 3, (4), 450-455.

(14) McMurdo, C. J.; Ellis, D. A.; Webster, E.; Butler, J.; Christensen, R. D.; Reid, L. K., Aerosol enrichment of the surfactant PFO and mediation of the water-air transport of gaseous PFOA. Environ. Sci. Technol. 2008, 42, (11), 3969-3974.

(15) Webster, E.; Ellis, D. A., Potential role of sea spray generation in the atmospheric transport of perfluorocarboxylic acids. Environ. Toxicol. Chem. 2010, 29, (8), 1703-1708

(16) Kirchgeorg, T.; Dreyer, A.; Gabrieli, J.; Kehrwald, N.; Sigl, M.; Schwikowski, M.; Boutron, C.; Gambaro, A.; Barbante, C.; Ebinghaus, R., Temporal variations of perfluoroalkyl substances and polybrominated diphenyl ethers in alpine snow. Environ. Pollut. 2013, 178, (0), 367-374.

(17) Gabrieli, J.; Vallelonga, P.; Cozzi, G.; Gabrielli, P.; Gambaro, A.; Sigl, M.; Decet, F.; Schwikowski, M.; Gaggeler, H.; Boutron, C.; Cescon, P.; Barbante, C., Post 17th-Century changes of European PAH emissions recorded in high-altitude alpine snow and ice. Environ. Sci. Technol.2010, 44, (9), 3260-3266.

(18) Li, Q. L.; Wang, N. L.; Wu, X. B.; Pu, J. C.; He, J. Q.; Zhang, C. W., Sources and distribution of polycyclic aromatic hydrocarbons of different glaciers over the Tibetan Plateau. Sci China Earth Sci 2011, 54, (8), 1189-1198.

(19) Maggi, V.; Villa, S.; Finizio, A.; Delmonte, B.; Casati, P.; Marino, F., Variability of anthropogenic and natural compounds in high altitude-high accumulation alpine glaciers. Hydrobiologia 2006, 562, 43-56.

(20) Ruggirello, R. M.; Hermanson, M. H.; Isaksson, E.; Teixeira, C.; Forsstrom, S.; Muir, D. C. G.; Pohjola, V.; van de Wal, R.; Meijer, H. A. J., Current use and legacy pesticide deposition to ice caps on Svalbard, Norway. J. Geophy. Res.-Atmos. 2010,115. DOI:10.1029/2010JD014005

(21) Carrera, G.; Fernandez, P.; Vilanova, R. M.; Grimalt, J. O., Persistent organic pollutants in snow from European high mountain areas. Atmos. Environ. 2001, 35, (2), 245-254.

(22) Villa, S.; Negrelli, C.; Maggi, V.; Finizio, A.; Vighi, M., Analysis of a firn core for assessing POP seasonal accumulation on an Alpine glacier. Ecotoxicol. Environ. Saf. 2006, 63, (1), 17-24.

(23) Villa, S.; Vighi, M.; Maggi, V.; Finizio, A.; Bolzacchini, E., Historical trends of organochlorine pesticides in an Alpine glacier. J. Atmos. Chem. 2003, 46, (3), 295-311. 
(24) Wang, X. P.; Xu, B. Q.; Kang, S. C.; Cong, Z. Y.; Yao, T. D., The historical residue trends of DDT, hexachlorocyclohexanes and polycyclic aromatic hydrocarbons in an ice core from Mt. Everest, central Himalayas, China. Atmos. Environ. 2008, 42, (27), 6699-6709.

(25) Wang, X. P.; Yao, T. D.; Wang, P. L.; Yang, W.; Tian, L. D., The recent deposition of persistent organic pollutants and mercury to the Dasuopu glacier, Mt. Xixiabangma, central Himalayas. Sci. Total Environ. 2008, 394, (1), 134-143.

(26) Macdonald, R. W.; Harner, T.; Fyfe, J., Recent climate change in the Arctic and its impact on contaminant pathways and interpretation of temporal trend data. Sci.Total Environ. 2005, 342, (1-3), 5-86.

(27) Shi, Y.; Pan, Y.; Yang, R.; Wang, Y.; Cai, Y., Occurrence of perfluorinated compounds in fish from Qinghai-Tibetan Plateau. Environ. Int. 2010, 36, (1), 46-50.

(28) Yao, T. D.; Thompson, L.; Yang, W.; Yu, W. S.; Gao, Y.; Guo, X. J.; Yang, X. X.; Duan, K. Q.; Zhao, H. B.; Xu, B. Q.; Pu, J. C.; Lu, A. X.; Xiang, Y.; Kattel, D. B.; Joswiak, D. Different glacier status with atmospheric circulations in Tibetan Plateau and surroundings. Nat. Clim. Chan. 2012, 2 (9), 663-667

(29) Tian, L.; Yao, T.; Li, Z.; MacClune, K.; Wu, G.; Xu, B.; Li, Y.; Lu, A.; Shen, Y., Recent rapid warming trend revealed from the isotopic record in Muztagata ice core, eastern Pamirs. J. Geophy. Res.-Atmos. 2006, 111, (D13). DOI: 10.1029/2005JD006249

(30) Xu, B.; Cao, J.; Hansen, J.; Yao, T.; Joswiak, R. D.; Wang, N.; Wu, G.; Wang, M.; Zhao, H.; Yang, W.; Liu, X.; He, J., Black soot and the survival of Tibetan glaciers. Proc. Nat. Acad. Sci. U.S.A. 2009, 106, 22114-22118.

(31) Taniyasu, S.; Kannan, K.; So, M. K.; Gulkowska, A.; Sinclair, E.; Okazawa, T.; Yamashita, N., Analysis of fluorotelomer alchols, fluorotelomer acids, and short- and long-chain perfluorinated acids in water and biota. J. Chromatogr.A 2005, 1093, 89-97.

(32) Zhao, Z.; Xie, Z.; Muller, A.; Sturm, R.; Tang, J.; Zhang, G.; Ebinghaus, R., Distribution and long-range transport of polyfluoroalkyl substances in the Arctic, Atlantic Ocean and Antarctic coast. Environ. Pollut. 2012, 170, (0), 71-77.

(33) Ahrens, L.; Barber, J. L.; Xie, Z.; Ebinghaus, R., Longitudinal and latitudinal distribution of perfluoroalkyl compounds in the surface water of the Atlantic Ocean. Environ. Sci. Technol. 2009, 43, (9), 3122-3127.

(34) van Leeuwen, S. P. J.; de Boer, J., Extraction and clean-up strategies for the analysis of poly- and perfluoroalkyl substances in environmental and human matrices. $J$. Chromatogr. A 2007, 1153, 172-185.

(35) Meyer, T.; De Silva, A. O.; Spencer, C.; Wania, F., Fate of perfluorinated carboxylates and sulfonates during snowmelt within an urban watershed. Environ. Sci.Technol. 2011, 45, (19), 8113-8119. 
(36) Tian, L.; Masson-Delmotte, V.; Yao, T.; Jouzel, J., Tibetan Plateau summer monsoon northward extent revealed by measurements of water stable isotopes. J. Geophy. Res.-Atmos. 2001, 106, (D22), 28081-28088.

(37) Li, Z.; Yao, T.; Tian, L.; Xu, B.; Li, Y., Atmospheric Pb variations in Central Asia since 1955 from Muztagata ice core record, eastern Pamirs. Chinese Sci. Bull. 2006, 51, (16), 1996-2000.

(38) Sheng, J.; Wang, X.; Gong, P.; Joswiak, D. R.; Tian, L.; Yao, T.; Jones, K. C., Monsoon-driven transport of organochlorine pesticides and polychlorinated biphenyls to the Tibetan Plateau: three year atmospheric monitoring study. Environ. Sci. Technol. 2013, 47, (7), 3199-3208.

(39) Butt, C. M.; Berger, U.; Bossi, R.; Tomy, G. T., Levels and trends of poly- and perfluorinated compounds in the arctic environment. Sci.Total Environ. 2010, 408, (15), 2936-2965.

(40) Hogue, C., Perfluorinated chemical controls. Chem. Eng. News Arch. 2012, 90, (37), 24-25.

(41) Houde, M.; De Silva, A. O.; Muir, D. C. G.; Letcher, R. J., Monitoring of perfluorinated compounds in aquatic biota: an updated review. Environ. Sci. Technol. 2011, 45, (19), 7962-7973.

(42) Kwok, K. Y.; Taniyasu, S.; Yeung, L. W. Y.; Murphy, M. B.; Lam, P. K. S.; Horii, Y.; Kannan, K.; Petrick, G.; Sinha, R. K.; Yamashita, N., Flux of perfluorinated chemicals through wet deposition in Japan, the United States, and several other countries. Environ. Sci. Technol. 2010, 44, (18), 7043-7049.

(43) Tao, L.; Ma, J.; Kunisue, T.; Libelo, E. L.; Tanabe, S.; Kannan, K., Perfluorinated compounds in human breast milk from several Asian countries, and in infant formula and dairy milk from the United States. Environ. Sci. Technol. 2008, 42, (22), 8597-8602.

(44) Scott, B. F.; Spencer, C.; Mabury, S. A.; Muir, D. C. G., Poly and perfluorinated carboxylates in North American precipitation. Environ. Sci. Technol. 2006, 40, 7167-7174.

(45) Loewen, M.; Wania, F.; Wang, F.; Tomy, G., Altitudinal transect of atmospheric and aqueous fluorinated organic compounds in Western Canada. Environ. Sci. Technol. 2008, 42, (7), 2374-2379.

(46) Cai, M.; Zhao, Z.; Yin, Z.; Ahrens, L.; Huang, P.; Cai, M.; Yang, H.; He, J.; Sturm, R.; Ebinghaus, R.; Xie, Z., Occurrence of perfluoroalkyl compounds in surface waters from the North Pacific to the Arctic Ocean. Environ. Sci. Technol. 2012, 46, (2), 661-668.

(47) Cai, M.; Yang, H.; Xie, Z.; Zhao, Z.; Wang, F.; Lu, Z.; Sturm, R.; Ebinghaus, R., Perand polyfluoroalkyl substances in snow, lake, surface runoff water and coastal seawater 
in Fildes Peninsula, King George Island, Antarctica. J. Hazard. Mater. 2012, 209, 335-342.

(48) Schenker, U.; Scheringer, M.; MacLeod, M.; Martin, J. W.; Cousins, I. T.; Hungerbhler, K., Contribution of volatile precursor substances to the flux of perfluorooctanoate to the Arctic. Environ. Sci.Technol. 2008, 42, (10), 3710-3716.

(49) Butt, C. M.; Muir, D. C. G.; Stirling, I.; Kwan, M.; Mabury, S. A., Rapid response of Arctic ringed seals to changes in perfluoroalkyl production. Environ. Sci.Technol. 2006, 41, (1), 42-49.

(50) Plassmann, M. M.; Meyer, T.; Lei, Y. D.; Wania, F.; McLachlan, M. S.; Berger, U., Laboratory Studies on the Fate of Perfluoroalkyl Carboxylates and Sulfonates during Snowmelt. Environ. Sci.Technol .2011, 45, (16), 6872-6878

(51) Li, J.; Del Vento, S.; Schuster, J.; Zhang, G.; Chakraborty, P.; Kobara, Y.; Jones, K. C., Perfluorinated compounds in the Asian atmosphere. Environ. Sci. Technol. 2011, 45, (17), 7241-7248.

(52) Paul, A. G.; Jones, K. C.; Sweetman, A. J., A first global production, emission, and environmental inventory for perfluorooctane sulfonate. Environ. Sci. Technol. 2008, 43, (2), 386-392.

(53) Ellis, D. A.; Martin, J. W.; De Silva, A. O.; Mabury, S. A.; Hurley, M. D.; Sulbaek Andersen, M. P.; Wallington, T. J., Degradation of Fluorotelomer Alcohols: A Likely Atmospheric Source of Perfluorinated Carboxylic Acids. Environ. Sci. Technol. 2004, 38, (12), 3316-3321.

(54) Ellis, D. A.; Martin, J. W.; Mabury, S. A.; Hurley, M. D.; Sulbaek Andersen, M. P.; Wallington, T. J., Atmospheric lifetime of fluorotelomer alcohols. Environ. Sci. Technol. 2003, 37, (17), 3816-3820.

(55) Arp, H. P. H.; Goss, K.-U., Gas/particle partitioning behavior of perfluorocarboxylic acids with terrestrial aerosols. Environ. Sci. Technol. 2009, 43, (22), 8542-8547.

(56) Ahrens, L.; Xie, Z.; Ebinghaus, R., Distribution of perfluoroalkyl compounds in seawater from Northern Europe, Atlantic Ocean, and Southern Ocean. Chemosphere 2009, 78, (8), 1011-1016.

(57) Dreyer, A.; Weinberg, I.; Temme, C.; Ebinghaus, R., Polyfluorinated compounds in the atmosphere of the Atlantic and Southern Oceans: evidence for a global distribution. Environ. Sci. Technol. 2009, 43, (17), 6507-6514.

(58) Ahrens, L.; Shoeib, M.; Del Vento, S.; Codling, G.; Halsall, C., Polyfluoroalkyl compounds in the Canadian Arctic atmosphere. Environ. Chem. 2011, 8, (4), 399-406. 
(59) Wang, X. P.; Gong, P.; Yao, T. D.; Jones, K. C., Passive air sampling of organochlorine pesticides, polychlorinated biphenyls, and polybrominated diphenyl ethers across the Tibetan Plateau. Environ. Sci. Technol. 2010, 44 (8), 2988-2993.

(60) Lehmler, H. J., Synthesis of environmentally relevant fluorinated surfactants- A review. Chemosphere 2005, 58, 1471-96.

(61) Cong, Z. Y.; Kang, S. C.; Gao, S. P.; Zhang, Y.; Li, Q.; Kawamura, K., Historical trends of atmospheric black carbon on Tibetan Plateau as reconstructed from a 150-year lake sediment record. Environ. Sci.Technol. 2013, 19, 2579-2586. 


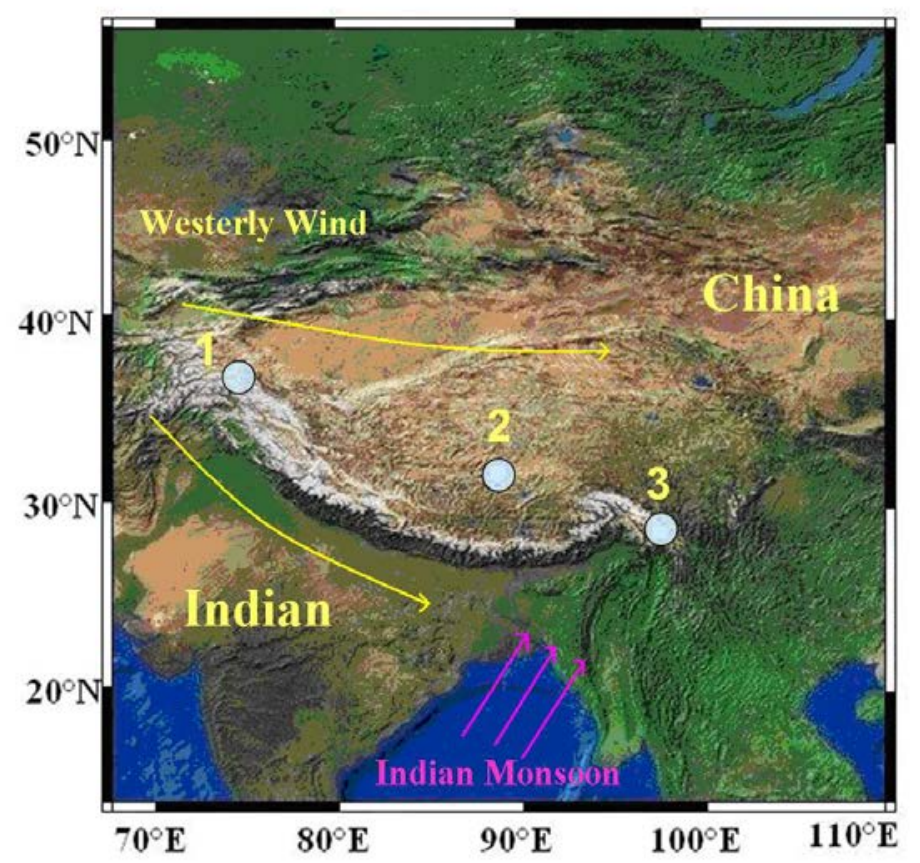

Figure 1 Schematic of air circulation systems and location of the sampling sites 1. Mt. Muztagata, 2. Namco Lake, 3. Mt. Zuoqiupu 
1

\begin{tabular}{|c|c|c|c|c|c|c|c|c|c|}
\hline \multicolumn{10}{|c|}{ Table 1 Comparison of the PFAAs concentrations $(\mathrm{pg} / \mathrm{L})$ obtained in this study with data from other remote regions } \\
\hline time & 1980-1999 & 1996-2007 & 2010 & 1996-2006 & 1996-2008 & 2006 & & 2002 & 2004 \\
\hline site & $\begin{array}{c}\text { Mt. } \\
\text { Muztagata } \\
\text { snow core }\end{array}$ & $\begin{array}{c}\text { Mt. } \\
\text { Zuoqiupu } \\
\text { snow core }\end{array}$ & $\begin{array}{c}\text { fresh } \\
\text { snow from } \\
\text { Namco }\end{array}$ & $\begin{array}{l}\text { Devon Island } \\
\text { icecap } \\
\text { (Canadian } \\
\text { Arctic) }\end{array}$ & $\begin{array}{l}\text { Colle Gnifetti } \\
\text { snow } \\
\text { (Swiss/Italian } \\
\text { Alps) }\end{array}$ & $\begin{array}{c}\text { Arctic } \\
\text { snow/sea ice }\end{array}$ & $\begin{array}{c}\text { Antarctic } \\
\text { snow }\end{array}$ & $\begin{array}{c}\text { Precipitation } \\
\text { of remote } \\
\text { Canada }\end{array}$ & $\begin{array}{c}\text { Remote lake } \\
\text { water, } \\
\text { Canada }\end{array}$ \\
\hline PFBS & ND & ND & BDL-5 & & & BDL-1500 & BDL-49.9 & & \\
\hline PFHpS & ND & ND & ND & & & & $12.2-219$ & & \\
\hline PFOS & 61.4-346 & $\mathrm{BDL}$ & $25-64.2$ & $1.4-86$ & & BDL-44 & $17.2-199$ & & $50-110$ \\
\hline PFBA & BDL & BDL-56.2 & $913-2569$ & & $340-1870$ & BDL-1000 & 76.6-1112 & & \\
\hline PFPA & 64.5-142 & BDL-49.8 & $94.5-3502$ & & BDL-210 & BDL-66 & BDL-203 & & \\
\hline PFHxA & $22-100$ & BDL-40.5 & $63.5-140$ & & $60-340$ & BDL-66 & $142-678$ & & \\
\hline PFHPA & ND & ND & $241-982$ & & $110-190$ & BDL-69 & & & \\
\hline PFOA & $40.8-243$ & $37.8-183$ & 68-191 & $13.1-147$ & $200-630$ & $39-710$ & 114-383 & $50-300$ & $720-1000$ \\
\hline PFNA & $10.3-41.2$ & BDL-73.4 & $49.2-90.8$ & $5.0-143$ & BDL-280 & $38-220$ & $23.7-114$ & $20-250$ & $300-750$ \\
\hline PFDA & $7.9-50$ & $1.2-75$ & $9.2-35.8$ & BDL-21.8 & BDL-240 & BDL-280 & BDL-111 & & $100-250$ \\
\hline PFUnDA & BDL-5.75 & ND & BDL-18.1 & BDL-27.3 & ND-180 & BDL-120 & BDL-263 & & BDL-200 \\
\hline PFDoDA & BDL-24.1 & ND & BDL-18.6 & & BDL-110 & BDL-75 & BDL-189 & & \\
\hline PFTriDA & ND & ND & ND & & & BDL-500 & BDL-485 & & \\
\hline PFTeDA & ND & ND & ND & & & BDl-81 & BDL-143 & & \\
\hline FOSA & ND & ND & ND & & & BDL-26 & & & \\
\hline Sum & $193-927$ & $37.3-370$ & $1875-4236$ & $20.8-436$ & $650-4060$ & $220-8100$ & 388-1309 & & \\
\hline Reference & & This study & & (8) & (16) & $(45)$ & (46) & (43) & (44) \\
\hline
\end{tabular}



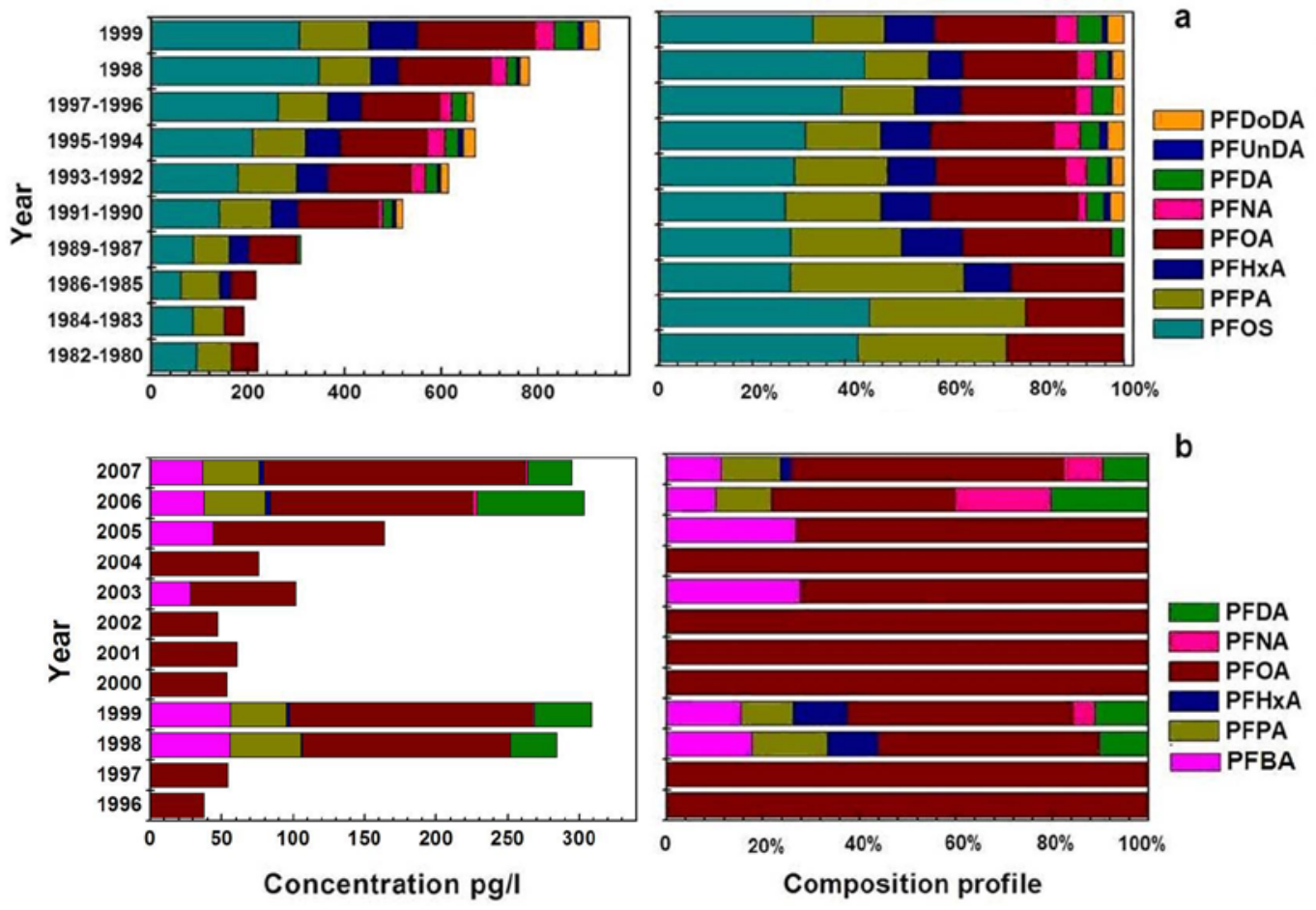

5

6 Figure 2 Time-series and composition profiles of individual PFAAs in Mt. Muztagata glacier (a) and Mt.Zuoqiupu glacier (b) 


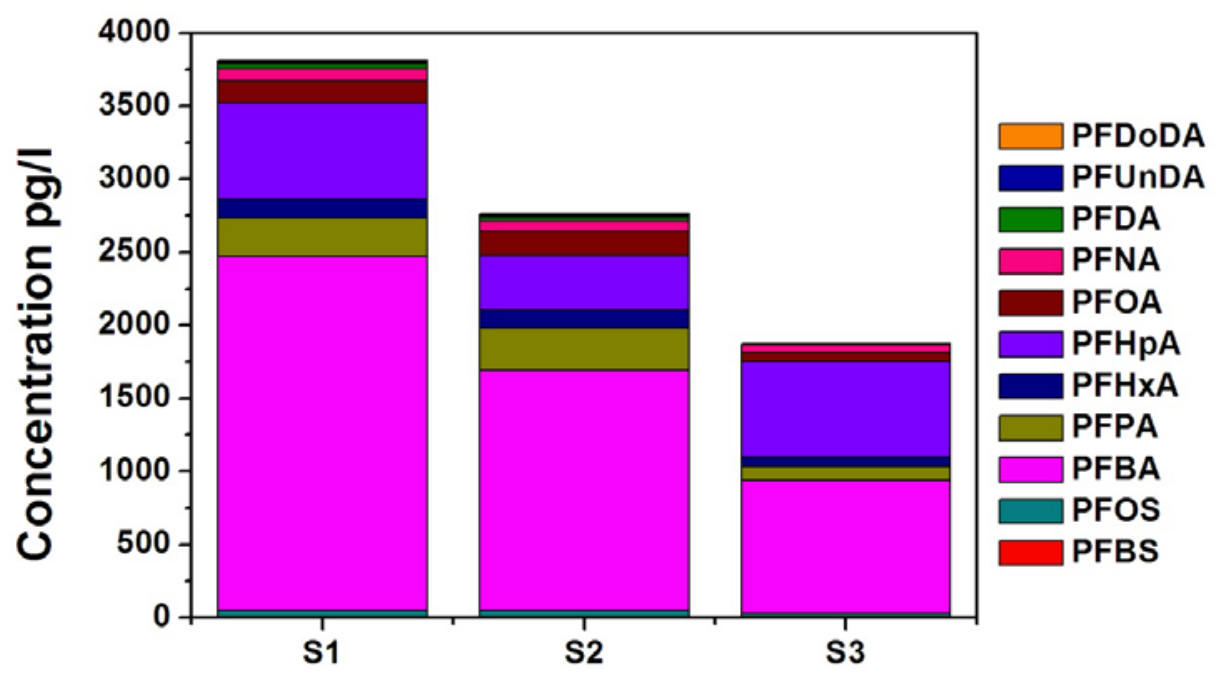

Figure 3 PFAAs concentrations in fresh snow collected at Namco 
